\title{
A General Model of Cost Accounting as an Application of AHP/ANP
}

\author{
Klaus Delimann \\ Institut fuer Unternehmensrechnung und Controlling, \\ Engehaldenstrasse 4, University of Bern, CH 3012 Bern / Switzerland \\ dellmann@iuc.unibe.ch
}

\begin{abstract}
Recently it was shown by the author (Dellmann, 1998, 1999a, 1999b), that cost accounting systems / models / concepts have the same structure as the AHP/ANP-model. Normally cost is measured in monetary units. But AHP/ANP has the advantage that we are able to introduce costs for intangibles, measured by the 1 to 9 Saaty-scale, and subsequently computed as a priority eigenvector. Thus we may combine cost in (normalized) monetary units and cost as a principal eigenvector for intangibles. In that respect the presented network-cluster-cost-model is a general form of cost accounting.
\end{abstract}

\section{Cost Accounting within the Firm}

Cost accounting is the process within a company where cost of different activities e.g. production is analysed and prepared for decision-making or control purposes. Within the conventional cost-accounting framework , costs are defined as either "direct" resp. „variabel cost" (i.e. costs which vary with the unit of activity) or "indirect" resp. „fixed overhead-cost" (i.e. costs incurred because of pre-existing commitments which the accountant will seek to allocate on some basis or other to activity units). Indirect costs are incurred as a result of a firm's long-run decision to produce. Costs always are measured in monetary units.

Cost accounting systems / models / concepts are a set of technological rules, which define how to record, evaluate and allocate costs to different objects, activities, or units. The allocation of costs to objects of costing for example to cost centers, processes, jobs or products is normaly done by the direct costing method. This method identifies andiaccumulates the costs that relate an object of costing. In certain cases we use a predetermined overhead rate by applying cost absorption. Examples for a cost allocation base to allocate manufacturing costs typically include labor-hours, machine-hours or production units. The cost accumulation - as a way of collecting costs in an organized fashion by means of a cost accounting system - is usually done either by job order or by process costing. A lot of different cost accounting systems are described in literature.

\section{The Cost-Accounting Process as a Network}

All production systems can be described, at the highest level of generality, as processes for the conversion of inputs into outputs. Since cost accounting is concerned with monitoring detailed system performance it must match the complexities of the system concerned. It is one of the cost accountant's tasks to form an opinion on the relationsship between cost and cost objects or cost activities in general and the degree to which variations in the costs concerned can be attributed to a given object or activity.

Within an organization we typically would expect to see flows of costs passing through various classifications or pools or clusters. For example product (flow) costing relies upon the idea that a final product and its cost are derived from a series of allocations to different levels or clusters structured hierarchicaly or more general in a network. This effect is explained by the following example, where we see the flow

- of total period cost

(cluster 1)

- to costs by type

(cluster 2) 
- to cost centres (with feedbacks)

- and finally to products

In this traditional model we have four clusters. Each cluster consists of a finite number of elements. Further classifications with respect to the split off in subclusters are of course possible, e.g. the separation of cluster 3 (cost centres) into the two subdivisons "service cost centres" and ,production cost centres". If we look to the clusterelements as nodes and the cost allocation as connections in form of arcs between one element in cluster $i$ and some or all the elements of any other cluster (node) $j$, cost accounting may be presented as a network or in more simple cases as a hierarchy. We call such a model a network-clustercost-model. A network is necessary when we have to consider interdependencies or feedbacks between elements of two or more clusters or between elements of one cluster. Usually we have such interdependencies, e.g. when cost centres provide themselves with goods and services.

\section{Cost Intensities for Tangible and Intangible Ressources}

Cost allocation (assignment, distribution) is thus represented as a directed graph or network. By appointment of a nonnegative number $0 \leq w_{i j} \leq 1$, called cost intensity, to an arc conducting from element $i$ to element $j$ we express the fact, that costs flow or are distributed from element $i$ to element $j$.

The main characteristic of the network-cluster cost-model lies in the use of cost intensities

- either derived from monetary cost amounts by normalizing them

- or derived by reciprocal paired comparisons for intangibles from which the principal eigenvector of cost-intensities is then computed.

Saaty, 1999 has shown how to combine tangibles with intangibles (see his paper on this symposion).

Cost intensities correspond to the priorities we know from AHP/ANP-models.

\section{Overall-Cost-Intensities - the Desired Result(s) of Cost Accounting}

As shown in theory, networks resp. hierarchies mathematically can be described by (super)matrices (see Saaty, 1996, p.83). Raising the matrix to powers - in a hierarchy depending of the number of levels concerned - we are able to compute the limiting priorities (cf. Saaty, 1996, p.126 f.) resp. the overallcost-intensities. These represent the desired results of cost accounting because the alternatives on the lowest level of a hierarchy are the calculation objects by definition.

\section{Conclusion}

We have seen that any technological cost accounting model can represented as a network - or in special cases as a hierarchy - of clusters, defined as objects of cost allocation. Cost intensities are derived either from monetary units (normalized) or by defined rules (in the case of cost absorption) or by pairwise comparisons in the case of having no monetary values for intangibles. An unmatched advantage of using network-cluster-cost-models is the integration of "costs" for intangibles into cost accounting. It's due to the research work of Th. L. Saaty that such a cost-accounting model is more general as any other costaccounting model using monetary units only.

\section{References}

DelImann, K. (1998) Innerbetriebliche und andere interdependente Leistungsverrechnungen im Netzwerk-Cluster-Kostenmodell. Die Unternehmung 52 (1998), 204-208

Dellmann, K. (1999a) Ein Allgemeines Modell einer entscheidungsorientierten Kostenrechnung. Zeitschrift fuer Betriebswirtschaft 69 (1999), 617- 642

Dellmann, K. (1999b) Das Netzwerk-Cluster-Kostenmodell - ein allgemeines Modell der Kostenrechnung IUC Working Paper (1998). Will be published in: Zeitschrift fuer betriebswirtschaftliche Forschung (end of 1999)

Saaty, Th.L. (1996) The Analytic Network Process. Pittsburgh. RWS Publications

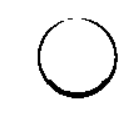

.

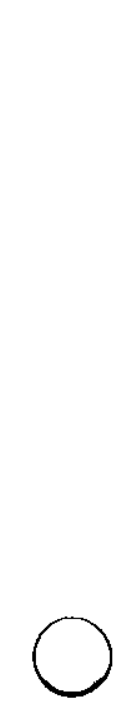

\section{.}

